\title{
Plickers: An ICT tool for formative assessment and feedback
}

\author{
K Uma Rao ${ }^{1}$, Prema $V^{2}$, K N Subramanya ${ }^{3}$ \\ RV College of Engineering, Mysore Road, Bangalore \\ ${ }^{1}$ umaraok@rvce.edu.in \\ ${ }^{2}$ premav@rvce.edu.in \\ ${ }^{3}$ subramanyakn@rvce.edu.in
}

\begin{abstract}
Worldwide, research and experience has shown that use of ICT (Information and Communication Technology) tools can lead to enhanced teaching methods and improve student learning attainment levels. Applications of ICT includes enabling access of course materials through remote devices, creation of on-line repositories for tutorials and lectures, flipped classrooms, use of devices and tools such as tablets, videos, projector, audio equipment etc. for teaching. The use of ICT for formative assessment and for course feedback, has not been highlighted. This paper presents, the tool "Plickers", its key features, its application for formative assessment and feedback, with a case study.
\end{abstract}

Keywords: Flipped Classroom, content development, peer instruction, think-pair-share

\section{Introduction}

Summative and formative assessments are two ways of evaluating students. In summative assessment, the students take a test at the end of the instruction. The assessment can be elaborate, include design, numerical problems and essay questions[1-4]. In formative assessment, the student learning is monitored continuously during the learning process, while the course is on-going. This will help the teacher modify the teaching and learning activities to improve attainment of the defined outcomes of the course [5-6]. Since the assessment is continuous, the questions should be crisp, conceptual and the answers, brief [7-8]. The teacher can even allot 5-10 minutes in each class for this. Objective type questions with multiple answers can be effectively used for this, since the time taken would be less. Until recently, summative assessment was more popular. However, with ICT, it is easy to conduct tests of objective type. After the completion of the course, the feedback of the students, is important as it is a reflection of the entire teaching learning process and the students' perception of the course. Feedback questions if framed properly can provide information that is instructor specific and course specific.

\author{
Corresponding Author \\ Prema V, Dept. of EEE, RV College of Engineering, \\ Bangalore \\ premav@rvce.edu.in
}

Thus, formative assessment and student feedback, done periodically, spread throughout the course, can be very effective in improving the student attainment levels, as they provide guidelines to the instructor for improvement. Plickers is a open-source web based tool, wherein the students can choose one answer from four options. Hence, it can be used for both formative assessment and for course feedback. This paper presents the use of Plickers in a course on Linear Integrated Circuit.

\section{Types of assessment}

Assessment is the way an instructor gathers data about the teaching and the students' learning [9-12].. Evaluation, therefore, draws on one's judgment to determine the overall achievement of an outcome, based on the assessment data. The next step is to analysis the results of evaluation, to identify weaknesses, gaps, deficiencies and to design steps to improve on the outcome. There are commonly three types of assessments.

i. Diagnostic assessment: This is to help the instructor identify the students' current knowledge of a subject, their skill sets and capabilities before teaching takes place. Knowing the students' strengths and weaknesses helps the instructor to plan the lessons more effectively. Diagnostic Assessment include pretests, self-assessments to identify skills and competencies, discussions and interviews. Diagnostic assessment is very important in teaching engineering students, as the instructor has to assess whether the student group has the necessary prerequisites to go forward with the course. 
ii. Summative assessment: This is used to evaluate student learning, skill acquisition, and academic achievement at the conclusion of a defined instructional period and compare it against a standard or benchmark. Summative assessment includes tests, assignments, or projects used to determine whether students have learned what they were expected to learn. These are given at the conclusion of a specific instructional period, and therefore they are generally evaluative, rather than diagnostic. Summative assessment results are often recorded as scores or grades that are then factored into a student's permanent academic record. Rubrics, developed around a set of standards or bench marks, can be used for summative assessment.

iii. Formative assessment: The main purpose of formative assessments is to move students' learning forward while their learning is still in the process of developing. Formative assessment measures student progress but it can also assess the effectiveness of the instructor. It operates as a feedback loop in which both the instructor and the students play active roles in enabling learning by consistently working throughout the course, to build and consolidate student's learning. For formative assessment to be effective it is vital for the instructor to be clear about the intended learning goals for a lesson. The teacher has to focus on what students will learn, as opposed to what they will do. The learning objectives have to be clearly defined. With clarity about the goal and indicators, teachers can then decide how they will gather evidence of learning. It is good practice to incorporate this type of assessment to 'test' students' knowledge before expecting all of them to do well in an examination. Framing Multiple Choice Questions during the course delivery, is a good strategy for formative assessment. The students can be asked to choose the answers. These objective questions have the following advantages:

$>$ It is free from the bias of the evaluator or instructor

$>$ Yardsticks for evaluation are unbiased

$>$ The evaluation is same for different examiners

$>$ Time is saved in writing lengthy answers

$>$ Student has to understand the lesson to answer correctly

\section{$>$ Finer aspects of the lesson can be questioned}

The number of students who answer correctly, is a direct indication of the learning outcome. If more number of students answer incorrectly, it's an indication to the instructor that the learning outcome has not been achieved. If the teacher spends a few minutes in every class to take a quick assessment, the learning outcomes will vastly be enhanced. This requires a tool to facilitate objective type questions to be performed quickly. Plickers is an excellent, simple to use tool for this.

\section{Course Feedback}

The feedback from the students after a course is vital to assess the outcomes of the course. Globally, higher education has been redefined as "Outcome Based Education (OBE)". A paradigm shift is taking place, where the learning outcomes are more important than teaching. Every teacher is to ask the question, "I am teaching, are they learning?". The answer to this is the essence of OBE. In this scenario, student feedback is very important. The feedback provides insight into different aspects of the course, briefly discussed here.

> Instructor specific issues: The feedback on specific issues about the instructor provides insight into the strengths and weaknesses of the instructor, providing ample scope for improvement. The feedback should include the presentation style of the instructor, the teaching tools used, the way concepts are presented, the organization of the content in each class, the body language of the instructor and personality traits such as punctuality, commitment, fairness, etc. This feedback is very individualistic and depends on the instructor.

$>$ Content: The feedback should include the clarity of the content presented, the instructional material such as presentations, videos, documents etc. provided, the guidance given about the content and the adequacy of the content.

D Outcomes: The feedback should indicate if the outcomes were defined to the students, and whether the tests, assignments and projects were oriented towards the assessment of the achievement of the outcomes.

$>$ Course end survey: The feedback should be specific to the course under study and the student's perception of the achievement of the outcomes. If the students feel that the outcomes defined by the instructor have not been achieved, then their grades have no meaning.

For the feedback to be meaningful, the instructor has to frame the questions and choices for answers, correctly. Leading and open ended questions should be avoided. Long complex questions should also be avoided. The number of questions have to be limited, so that the 
students do not lose interest in answering them. Hence, the instructor has to choose the most relevant and necessary points on which feedback is needed. The students can be given about four options to choose from. Plickers, is an excellent tool to get a quick feedback.

\section{Plickers}

Plickers is an assessment tool for a quick and simple way to check student understanding. This assessment tool allows instructors to collect on-the-spot formative assessment data and feedback without the need to have students use devices or paper and pencil. Teachers can use this tool with previous planning or on the go as needed. It provides students with the opportunity to participate and engage in learning without feeling self-conscious. It's a data collection tool that's helpful for teachers and fun for the students.

Plickers is a free web based tool that combines response clickers and QR codes. With hand held clickers, the students click the letter (A,B,C ,D ) or the number $(1,2,3,4)$ of the correct answer, for a multiple choice question. In Plickers the students do a similar exercise using a Plicker card, as shown in Fig 1.

A Plicker card is an image similar to a QR code on a piece of paper that can be scanned by a tablet or a smart phone (Fig 1). Depending on which way a student holds the Plicker image, the response to a question created within the app on the smart phone or Plickers website can be determined. Simple to use, Plickers can help instructors collect valuable data to monitor student progress. A quick assessment can be done at the beginning or ending of every class.

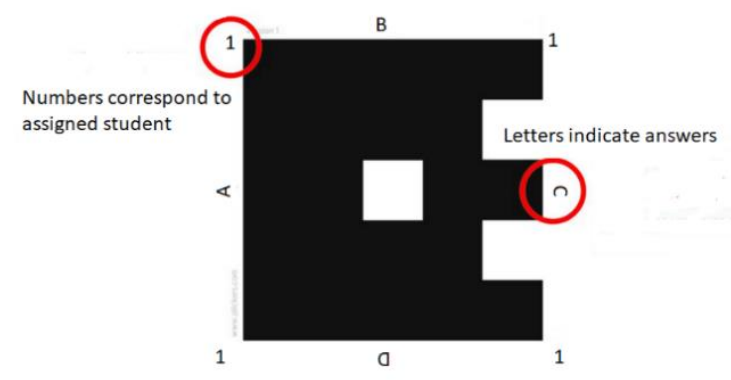

Fig 1 : Plicker Card

\section{Procedure to use Plickers}

Plickers is an online tool which can be used by signing up to plickers' website. It is possible to add different classes and students to the account. Plickers automatically assign cards to students as the names are entered. New libraries are created and multiple choice questions and true/false questions are added to the library.

Plickers mobile app is required to collect response of the students. Each student is given a card and the questions are played from the library. The students hold the cards upright with their choice of answers positioned on the card. While scanning the cards, it should be made sure that both the mobile app and website are logged in with the same account. Plickers instantly scans the cards and record the response of each student. Reports can be generated and downloaded in required format. Scoresheets are special feature available to monitor progress of individual student.

\section{Case Studies}

Two case studies are considered here to demonstrate the effectiveness of functions and uses of Plicker. The first case has a set of multiple choice questions as a part of formative assessment and in the second case, Plickers is used to take feedback.

\section{A. Case 1:Formative Assessment}

The course selected for this case study is Linear Integrated Circuit. This is a UG course which starts with the basics of operational amplifier (op-amp) and deals with various applications of op-amp. Multiple choice questions were formed on basic concepts of op-amp and uploaded in plicker web. At the end of every lecture, these questions were displayed in the class from. Students were provided with plicker cards. Once a question is displayed, the students are supposed to show their cards with their choice of answer displayed on the top of the card. The cards are scanned using Plickers mobile app. When all the cards are scanned, the reports and scorecards would be ready in the app. Fig 2 shows some of the questions uploaded to plicker website. 


\begin{tabular}{|c|c|}
\hline ¿ New Set & \\
\hline Recent & \\
\hline Y Your Library & \\
\hline 目 Reports & \\
\hline "II Scoresheet... & \\
\hline Your Classes & $A$ a sq \\
\hline Demo Class & B a fu \\
\hline III Sem & C a ha \\
\hline Linear Integrated .. & D a sit \\
\hline$\oplus$ New Class & \\
\hline New Pack & If \\
\hline & $\begin{array}{l}\text { differ } \\
\text { dB re } \\
\text { mode }\end{array}$ \\
\hline & A $50 \mathrm{~d}$ \\
\hline & B $23 c$ \\
\hline & C $25 \mathrm{~d}$ \\
\hline & D 46 \\
\hline
\end{tabular}

The most commonly used amplifier in sample and hold circuit is

\footnotetext{
A an inverting amplifier with a gain of 100

B a unity gain non inverting amplifier

C an inverting amplifier with a gain of 10

D a unity gain inverting amplifier
}

\section{A good quality op amp has}

\author{
A narrow bandwidth \\ B Very large bandwidth \\ C low differential gain \\ D high selectivity
}

Fig. 2 Questions uploaded to Plickers website

\begin{tabular}{|c|c|c|c|c|c|c|c|c|}
\hline First name & Last Name & Score & Correct & Answered & Q1 & Q2 & Q3 & Q4 \\
\hline 1RV14EE045 & Shashank Agarwal & $50 \%$ & 2 & 4 & $\mathrm{~A}$ & $\mathrm{~B}$ & $\mathrm{~A}$ & $\mathrm{~B}$ \\
\hline 1RV15EE024 & Ndraganti Vineeth Sarma & $100 \%$ & 4 & 4 & $\mathrm{~A}$ & $\mathrm{~B}$ & $\mathrm{D}$ & $\mathrm{C}$ \\
\hline 1RV15EE043 & Rakshitha K V & $50 \%$ & 2 & 4 & $\mathrm{D}$ & B & $\mathrm{D}$ & $\mathrm{B}$ \\
\hline 1RV16EE011 & Apeksha Manjunath Angadi & $100 \%$ & 4 & 4 & - & A & $\mathrm{D}$ & $\mathrm{C}$ \\
\hline 1RV16EE044 & Puneeth S & $100 \%$ & 4 & 4 & $\mathrm{~B}$ & A & $\mathrm{D}$ & $\mathrm{D}$ \\
\hline 1RV16EE049 & Saransh Kushwaha & $100 \%$ & 4 & 4 & A & $\mathrm{D}$ & $\mathrm{D}$ & $\mathrm{C}$ \\
\hline 1RV17EE001 & Aayush Sharma & $100 \%$ & 4 & 4 & A & $\mathrm{D}$ & $\mathrm{D}$ & $\mathrm{C}$ \\
\hline 1RV17EE002 & Anantha S Udupa & $100 \%$ & 4 & 4 & - & $\mathrm{B}$ & - & $\mathrm{B}$ \\
\hline 1RV17EE003 & Anjana S & $50 \%$ & 2 & 4 & A & - & - & A \\
\hline 1RV17EE004 & Anjum Shariff & $25 \%$ & 1 & 4 & - & - & - & - \\
\hline 1RV17EE005 & Arshad A Yakeen & $100 \%$ & 4 & 4 & - & - & $\mathrm{D}$ & - \\
\hline 1RV17EE006 & Ashwini & $50 \%$ & 2 & 4 & A & A & - & - \\
\hline 1RV17EE007 & Athmiya V & $67 \%$ & 2.5 & 4 & - & $\mathrm{B}$ & $\mathrm{B}$ & $\mathrm{B}$ \\
\hline 1RV17EE028 & M K Narasimha & $72 \%$ & 3 & 4 & A & $\mathrm{D}$ & $\mathrm{D}$ & $\mathrm{D}$ \\
\hline 1RV17EE029 & Madhusudhan N & $36 \%$ & 1.2 & 4 & A & $\mathrm{B}$ & $\mathrm{B}$ & $\mathrm{C}$ \\
\hline 1RV17EE030 & Mandira Muddapur & $85 \%$ & 3.5 & 4 & A & $\mathrm{D}$ & $\mathrm{D}$ & $\mathrm{C}$ \\
\hline 1RV17EE031 & Muthulakshmi S & $13 \%$ & 0.5 & 4 & $\mathrm{~A}$ & $\mathrm{~A}$ & $\mathrm{~B}$ & $\mathrm{C}$ \\
\hline
\end{tabular}

Fig. 3 : Sample report generated in Plicker 
Fig 3 shows the report generated in Plicker. The software provides a number of options to generate report. Reports can be generated for individual students, a set of students or the entire class.

This exercise was done once in a week for the course linear integrated circuits. The students were found to be interested in using plickers. The main advantage of this tool is that it takes very less time to conduct short quizzes in the class. The evaluation and analysis of the results are automatic which saves time.

The usage of plicker for the course showed tremendous improvement in students' results. The same instructor was handling the course linear integrated circuits for two consecutive years 2017 and 2018. In 2018, plickers was used to conduct quizzes every week in the class. The helped students to make the concepts clear. This was very clearly visible in the results. Table 1 shows the result analysis for the same course for two years. Number of students who scored different grades in Continuous Internal Evaluation (CIE) and Semester End Examination (SEE) marks are tabulated in table 1 . The numbers shows that the number of students who scored S and A grades are higher in the year when more number of quizzes are conducted using plickers.
Table 2. Result Analysis

\begin{tabular}{|r|r|r|r|r|}
\hline & \multicolumn{2}{|c|}{$2017-18$} & \multicolumn{2}{c|}{ 2018-19 } \\
\hline & CIE & SEE & CIE & SEE \\
\hline S & 2 & -- & 8 & 6 \\
\hline A & 17 & 10 & 28 & 27 \\
\hline B & 20 & 23 & 12 & 12 \\
\hline C & 18 & 22 & 8 & 12 \\
\hline D & 6 & 8 & 3 & 5 \\
\hline E & 5 & 2 & 3 & 2 \\
\hline F & & 8 & & 1 \\
\hline
\end{tabular}

\section{B. Case 2:Course Feedback}

In this case, plickers is used to take feedback. In the course, linear integrated circuits, many ICT tools were used in course delivery such as content management systems with user defied websites, flipped classroom, etc. At the end of the course, an overall feedback was taken using Plickers to know whether the usage of ICT tools were useful for the students or not. Table 2 shows the questions and feedback given by each student. Fig 4 is the snapshot of plicker report for a few questions.

Prior to the use of Plickers, feedback and course-end surveys were taken manually. The tabulation and analysis of feedback were tedious and time consuming. The use of Plickers made the entire process very simple. The major advantage is that analysis ad reports would be ready as soon as the feedback is over.

Table 2. Questionnaire for feedback

\begin{tabular}{|c|c|c|c|c|c|}
\hline Question & 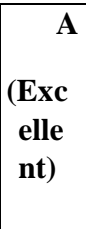 & $\begin{array}{l}\quad \text { B } \\
\text { (Ve } \\
\text { ry } \\
\text { Go } \\
\text { od) }\end{array}$ & $\begin{array}{l}\text { Q } \\
\text { (G } \\
\text { oo } \\
\text { d) }\end{array}$ & $\begin{array}{l}\text { I } \\
(\mathbf{N} \\
\text { o) }\end{array}$ & $\begin{array}{l}\text { Student } \\
\text { s } \\
\text { Feedbac } \\
\text { k } \\
(\%)\end{array}$ \\
\hline $\begin{array}{l}\text { Is the wikispace site simple } \\
\text { and easy to access? }\end{array}$ & 35 & 22 & 6 & 2 & 84.62 \\
\hline $\begin{array}{l}\text { Are the contents provided } \\
\text { clear? }\end{array}$ & 40 & 15 & 8 & 2 & 85.77 \\
\hline
\end{tabular}




\begin{tabular}{|l|l|l|r|r|r|}
\hline $\begin{array}{l}\text { Were the course notes and } \\
\text { the presentations provided } \\
\text { sufficient to understand the } \\
\text { concepts? }\end{array}$ & 38 & 18 & 6 & 3 & 85.00 \\
\hline $\begin{array}{l}\text { Were the videos provided } \\
\text { for the flipped class room } \\
\text { activity simple and } \\
\text { sufficient? }\end{array}$ & 32 & 16 & 5 & 12 & 76.15 \\
\hline $\begin{array}{l}\text { Do you find the flipped } \\
\text { class with solving } \\
\text { numericals in the class } \\
\text { better than the traditional } \\
\text { class room? }\end{array}$ & 36 & 23 & 4 & 2 & 85.77 \\
\hline $\begin{array}{l}\text { How is your overall } \\
\text { experience using ICT tools } \\
\text { for learning? }\end{array}$ & 41 & 11 & 10 & 3 & 84.62 \\
\hline
\end{tabular}

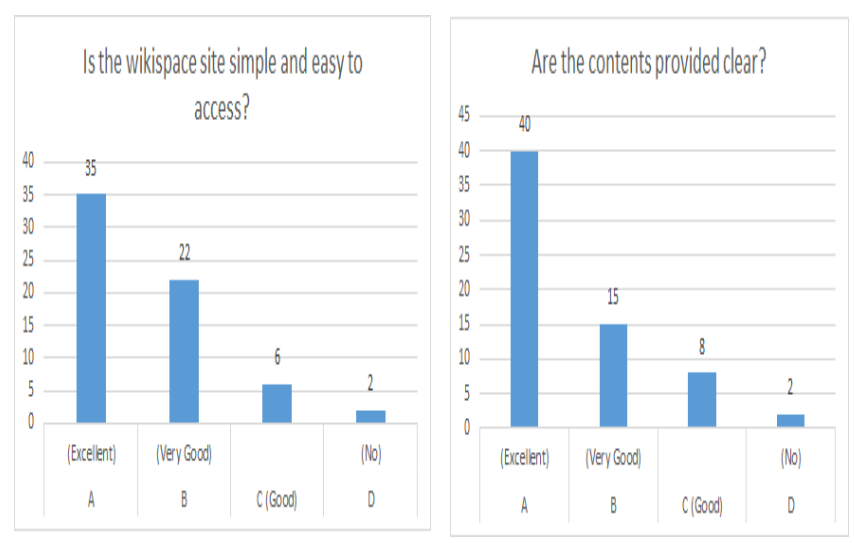

Fig. 4 Snapshot of the report generated in Plicker

\section{Conclusion}

This paper discusses the effectiveness of usage of a tool named Plicker in teaching and assessment. The impact of regular formative assessment and course feedback is very high in the process of teaching-learning. Plicker is an easyto-use, free web based tool which is very efficient and interesting for both instructor and students. This paper demonstrates the application of plicker for formative assessment and course feedback. The case studies shows that this tool is very powerful and fast in evaluation. The instructor can use it at the end of every lecture. It has the advantage that the reports are generated automatically as soon as the scanning of the cards is over. Thus the instructor need not spent extra time on evaluation and analysis. A feedback on the overall experience on the usage of ICT tools was the second case study. The students thoroughly enjoyed the use of Plickers.

\section{References}

[1] Abrams, L. M., \& McMillan, J. H. (2013). The instructional influence of interim assessments: Voices from the field. In R. W. Lissitz (Ed.), Informing the practice of teaching using formative and interim assessment (pp. 105-133). Charlotte, NC: Information Age Publishing.

[2] Andrade, H. L. (2010). Students as the definitive source of formative assessment: Academic selfassessment and self-regulation of learning. In H. L. Andrade \& G. J. Cizek (Eds.), Handbook of formative assessment (pp. 90-105). New York: Routledge.

[3] Atkinson, R. C., \&Geiser, S. (2009). Reflections on a century of college admissions tests. Educational Researcher, 38(9), 665-676.

[4] Goertz, M. E., Oláh, L. N., \&Riggan, M. (2009). From testing to teaching: The use of interim assessments in classroom instruction. Consortium for Policy Research in Education Research Report \# RR65.

[5] Illinois State Board of Education (ISBE). (2013, February). Guidebook on student learning objectives for Type III assessments. Illinois State Board of Education Performance Evaluation Advisory Council.

[6] Miami-Dade County Public Schools. (2008, October). How interim assessments affect student achievement. Information Capsule: Research Services, vol. 0804. Available: http://drs.dadeschools.net/InformationCapsules/IC080 4.PDF

[7] Thorsen, C., \&Cliffordson, C. (2012). Teachers' grade assignment and the predictive validity of criterionreferenced grades. Educational Research and Evaluation, 18(2), 153-172.

[8] Wiliam, D. (2010). An integrative summary of the research literature and implications for a new theory of formative assessment. In H. L. Andrade \& G. J. Cizek (Eds.), Handbook of Formative Assessment (pp. 18-40). New York: Routledge.

[9] Hanna, G. S., \&Dettmer, P. A. (2004). Assessment for effective teaching: Using context-adaptive planning. Boston, MA: Pearson A\&B

[10] Anton Havnes, Kari Smith, Olga Dysthe, Kristine Ludvigsen, Formative assessment and feedback: Making learning visible, Studies in Educational Evaluation, Volume 38, Issue 1, 2012, Pages 21-27, ISSN 0191-491X, https://doi.org/10.1016/j.stueduc.2012.04.001.

[11] Mishra, Richa, and Ketan Kotecha. "Students engagement through gamification in education gamifying formative assessment." Journal of Engineering Education Transformations (2017).

[12] Mishra, Richa, and K. Kotecha. "Formative Assessment through Computer Mediation: Enriching Student Engagement." Journal of Engineering Education Transformations (2015): 87-92. 